\title{
Caracterização Enzimática e Patogenicidade Cruzada de Colletotrichum spp. Associados a Doenças de Pós-Colheita*
}

\author{
Rinaldo M. Lima Filho' ${ }^{1 * *}$, Sônia M. A. Oliveira ${ }^{1}$ \& Maria Menezes $^{1}$ \\ ${ }^{1}$ Departamento de Agronomia, Área de Fitossanidade, Universidade Federal Rural de Pernambuco, CEP 52171-900, Recife, PE, \\ e-mail: smaoliveira@bol.com.br
}

(Aceito para publicação em 26/09/2003)

Autor para correspondência: Sônia Maria Alves de Oliveira

LIMA FILHO, R.M., OLIVEIRA, S.M.A. \& MENEZES, M. Caracterização enzimática e patogenicidade cruzada de Colletotrichum spp. associados a doenças de pós-colheita. Fitopatologia Brasileira 28:620-625. 2003.

\section{RESUMO}

A antracnose, causada por Colletotrichum spp., pode ocasionar grandes perdas a nível de campo e em pós-colheita sobre diversas culturas e seus produtos. O presente trabalho teve por objetivos testar a patogenicidade cruzada de isolados de C. gloeosporioides do caju (Anacardium occidentale) (CAJ), manga (Mangifera indica) (MG), mamão (Carica papaya) (MM), maracujá (Passiflora edulis) (MR) e C. musae da banana (Musa spp.) (BAJ); avaliar a produção de enzimas extracelulares (amilolítica, celulolítica, lipolítica e proteolítica) produzidas pelos isolados em substratos sólidos específicos; e detectar padrões eletroforéticos de proteínas totais e isoenzimas ( $\alpha$-esterase, $\beta$-esterase, fosfatase ácida e leucina aminopeptidase). $\mathrm{Na}$ análise da patogenicidade cruzada, todos os isolados de Colletotrichum spp. induziram lesões necróticas, deprimidas sobre os frutos, exceto em maracujá que foi suscetível tão somente ao isolado MR. Quanto à produção de enzimas extracelulares hidrolíticas, os isolados de C. gloeosporioides produziram amilase, lipase, protease e celulase, sendo que esta última enzima não foi detectada em C. musae. Com relação à análise eletroforética de proteínas totais e isoenzimas, os isolados apresentaram variações no número e posição das bandas no gel de poliacrilamida em todos os sistemas, com exceção de leucina aminopeptidase, onde bandas monomórficas foram formadas, sem variação na intensidade e pouca variação na mobilidade relativa.

Palavras-chave adicionais: Colletotrichum gloeosporioides, C. musae, patogenicidade, eletroforese de proteínas e isoenzimas.

\section{ABSTRACT}

Enzymatic characterization and crossed pathogenicity of Colletotrichum spp. associated with postharvest diseases

Anthracnose caused by Colletotrichum spp. may result in great losses in field productions and post-harvest conditions for several cultures and their products. The objective of this work was to test the pathogenicity of $C$. gloeosporioides isolates from cashew (Anacardium occidentale) (CAJ), mango (Mangifera indica) (MG), papaya (Carica papaya) (MM) and passion fruit (Passiflora edulis) (MR) and C. musae from banana (Musa spp.) (BAJ); to evaluate the production of extra cellular hydrolytic enzymes (amylolytic, celullolytic, lypolytic, proteolytic) by the isolates on specific solid culture media; and to detect electrophoretic patterns of total proteins and isoenzymes ( $\alpha$-esterase, $\beta$-esterase, acidic phosphatase and leucine aminopeptidase). In crossed pathogenicity tests, all Colletotrichum spp. isolates produced necrotic and depressed lesions on fruits, except on passion fruit, which was susceptible only to the MR isolate. The isolates of $C$. gloeosporioides produced amylolytic, lypolytic, proteolytic, and celullolytic enzymes, and C. musae did not produce any detectable celulase. Electrophoretic analysis of total proteins and isoenzymes showed variations in the number and position of the bands among all isolates in the systems used, except for leucine aminopeptidase, which was monomorphic.

\section{INTRODUÇÃo}

A antracnose causada por espécies de Colletotrichum é a principal doença de frutos em pós-colheita nas regiões tropicais e subtropicais do mundo, como a banana (Musa spp.), o caju (Anacardium occidentale L.), a manga (Mangifera indica L.), o mamão (Carica papaya L.) e o maracujá (Passiflora edulis f. flavicarpa Deg.) (Benato, 1999; Peres et al., 2002). O sintoma típico da doença é caracterizado por lesões arredondadas, grandes, necróticas e bordos ligeiramente elevados com o centro dos tecidos deprimidos, onde são produzidas massas de conídios de coloração alaranjada

\footnotetext{
*Parte da dissertação do primeiro autor. Universidade Federal Rural de Pernambuco (2003)

***Bolsista CAPES
}

(Bailey et al., 1992), podendo ocorrer uma podridão-mole nos frutos, prejudicando a sua comercialização (Lima et al.,1993).

De acordo com Muniz et al. (1998), a variabilidade de isolados de Colletotrichum gloeosporioides (Penz) Penz \& Sacc. sugere a existência de grupos de especialização patogênica. Assim, numerosos casos têm sido reportados, nos quais, espécies e biótipos de Colletotrichum estão associados a um único hospedeiro (Smith \& Black, 1990). Testes de patogenicidade em inoculações cruzadas em diversos hospedeiros são usados como forma de caracterização patogênica entre isolados (Denoyes \& Baudry, 1995; Muniz et al., 1998; Furtado et al., 1999; Peres et al., 2002), visando demonstrar a especificidade ou a gama de hospedeiros dos isolados ou espécies distintas.

Por meio da determinação da atividade enzimática de 
fungos por difusão em substratos sólidos específicos, diversos autores (Neirotti \& Azevedo, 1988; Paterson \& Bridge, 1994) têm demonstrado a maior ou menor capacidade de fungos produzirem as enzimas lipase, protease, amilase e celulase. Desta forma, tem-se um método adicional e simples para diferenciar espécies ou caracterizar isolados de uma mesma espécie (Hankin \& Anagnostakis, 1975).

Segundo Micales et al. (1988), isoenzimas podem ser usadas como marcadores para estimar a variabilidade de populações ou espécies de fungos. Padrões eletroforéticos de isoenzimas representam uma expressão direta do genoma de um organismo, podendo ser de valor considerável na determinação da variação entre os loci de diferentes enzimas (Boshoff et al., 1996).

Este trabalho teve como objetivos caracterizar isolados de C. gloeosporioides do maracujá, manga, mamão, caju e de C. musae (Berk. \& Curtis) Arx. (=C. gloeosporioides f.sp. musae) da banana, quanto à patogenicidade através de inoculações cruzadas; avaliar a atividade de enzimas extracelulares produzidas pelos isolados em substratos sólidos específicos; e detectar padrões de proteínas totais e isoenzimas, de modo a fornecer subsídios básicos para diferenciação segura dos isolados utilizados.

\section{MATERIALEMÉTODOS}

\section{Obtenção de isolados de Colletotrichum spp.}

Isolados de C. gloeosporioides foram obtidos de frutos apresentando sintomas de antracnose, nas seguintes espécies: caju, manga, mamão, maracujá-amarelo e C. musae de banana, os quais receberam as respectivas siglas: CAJ; MG; MM; MR e BAN. Os experimentos foram realizados no Laboratório de Patologia Pós-Colheita e no Laboratório de Micologia da Universidade Federal Rural de Pernambuco.

Os frutos foram lavados com água e sabão e, em seguida, fragmentos da área de transição da lesão foram retirados, desinfestados com álcool $50 \%$, hipoclorito de sódio $1,5 \%$ e duas porções de água destilada esterilizada (ADE) e retirado o excesso de umidade em papel de filtro esterilizado. Os fragmentos foram plaqueados em meio batata-dextroseágar (BDA) e incubados em condições de laboratório a temperatura de $25 \pm 2{ }^{\circ} \mathrm{C}$ até o crescimento do fungo, o qual foi transferido para tubos de ensaio, contendo meio BDA.

\section{Patogenicidade cruzada entre isolados de Colletotrichum spp. em diferentes hospedeiros}

Frutos sadios de banana, cv. Prata, de caju, de manga, cv. Tommy Atkins, de mamão, cv. 'Sunrise Solo' e de maracujáamarelo, em fase intermediária de maturação, foram lavados com água corrente e sabão, tratados com solução de hipoclorito de sódio a $1,5 \%$, por 2 min, lavados por duas vezes em $\mathrm{ADE}$ e secos sobre papel toalha em temperatura ambiente. O inóculo, com cinco dias de incubação, constituiuse de discos de meio de cultura (6 mm de diâmetro) contendo estruturas dos patógenos.

Procederam-se as inoculações dos frutos com os isolados de Colletotrichum spp., onde cada fruto foi inoculado com os isolados das demais hospedeiras. Os frutos foram previamente feridos com um perfurador flambado, e sobre a superfície foram depositados discos contendo estruturas do patógeno. Em seguida, os frutos foram colocados em câmara úmida, constituída de um saco plástico e um chumaço de algodão umedecido em ADE, por 48 h. A testemunha absoluta foi composta por um disco de BDA sobre o ferimento sem conter as estruturas do patógeno, e a testemunha relativa recebeu o isolado do seu hospedeiro de origem. As avaliações foram feitas aos sete dias após a inoculação medindo-se o diâmetro das lesões em dois sentidos diametralmente opostos. Foi realizado o reisolamento e a comparação dos isolados. O delineamento estatístico foi inteiramente casualizado em esquema fatorial 5 x 5 (cinco isolados x cinco espécies de frutas), com cinco repetições. Os dados foram submetidos à análise de variância e teste de Tukey a 5\% de probabilidade, para comparação das médias.

\section{Caracterização enzimática, eletroforética de proteínas totais e isoenzimas produzidas pelos isolados de Colletotrichum spp.}

Os protocolos para atividade amilolítica e proteolítica, celulolítica, lipolítica, estão de acordo com Paterson \& Bridge (1994), Neirotti \& Azevedo (1988) e Hankin \& Anagnostakis (1975), respectivamente.

O delineamento estatístico utilizado foi o inteiramente casualizado com cinco repetições por tratamento. Os dados foram submetidos à análise de variância e teste de Tukey a 5\% de probabilidade para comparação das médias.

Para a análise eletroforética de proteínas totais e isoenzimas ( $\alpha$-esterase, $\beta$-esterase e leucina aminopeptidase) utilizou-se a metodologia descrita por Alfenas et al. (1991).

Os perfis eletroforéticos apresentados pelos isolados, repetidos por duas vezes, foram analisados comparativamente em função do número de bandas visualizadas, intensidade de coloração (forte, média, fraca) e mobilidade relativa (Rf). A mobilidade relativa foi calculada de acordo com a fórmula descrita por Alfenas et al. (1991). Com os valores da mobilidade relativa das bandas formadas pelos isolados de Colletotrichum spp., no gel de poliacrilamida, foram calculados os coeficientes de similaridades (Cs) para todos os pares possíveis, conforme Hansen et al. (1986).

\section{RESULTADOS E DISCUSSÃO}

O teste de patogenicidade cruzada revelou a suscetibilidade dos frutos do maracujazeiro somente ao isolado MR, não sendo observados sintomas causados pelos demais isolados testados, aos sete dias após as inoculações (Tabela 1). No entanto, a banana se mostrou suscetível a todos os isolados testados, sendo a maior lesão provocada pelo isolado BAN, diferindo dos demais isolados. Com relação aos frutos de caju, manga e mamão, verificaram-se lesões provocadas pelos isolados BAN, CAJ, MG, MM, observando-se 


\section{R.M. Lima Filho et al.}

diferenças estatísticas e variação em virulência, porém, não sendo observada patogenicidade do isolado MR aos frutos. As maiores lesões foram produzidas pelos isolados em seus hospedeiros de origem, exceto o isolado MG inoculado em caju (Tabela 1). Fato semelhante foi observado por Peres et al. (2002), onde isolados de Colletotrichum spp. mostraramse mais agressivos a seus hospedeiros de origem. Também, Muniz et al. (1998) verificaram que o isolado de $C$. gloeosporioides proveniente do cajueiro não provocou lesão no maracujá, o que sugere a existência de grupos de especialização patogênica.

Os isolados de Colletotrichum spp. testados mostraram capacidade em produzir as enzimas hidrolíticas amilase, celulase, lipase e protease, detectadas através dos halos de degradação presente nos meios sólidos específicos.

Em relação à atividade amilolítica, o isolado $\mathrm{MM}$ apresentou maior halo de degradação de amido $(22,5 \mathrm{~mm})$, o qual diferiu dos demais isolados, enquanto que BAN, CAJ, MG, MR, mesmo tendo produzido a enzima, não diferiram entre si (Tabela 2). De acordo com Dianese (1990), as amilases

TABELA 1 - Patogenicidade cruzada entre isolados de Colletotrichum spp. avaliada através do diâmetro das lesões $(\mathrm{mm})$ em frutos tropicais inoculados após sete dias

\begin{tabular}{|c|c|c|c|c|c|}
\hline \multirow{2}{*}{ Isolado } & \multicolumn{5}{|c|}{ Hospedeiro } \\
\hline & Banana & Caju & Manga & Mamão & Maracujá \\
\hline BAN & $30,00 a^{*}$ & $7,40 \quad b$ & $7,40 \quad b$ & 6,00 & $0,00 \mathrm{~b}$ \\
\hline CAJ & $10,82 \mathrm{~b}$ & $15,00 \mathrm{a}$ & $20,60 \mathrm{a}$ & $23,50 \mathrm{a}$ & $0,00 \mathrm{~b}$ \\
\hline MG & $8,40 \mathrm{~b}$ & $16,90 \mathrm{a}$ & $22,00 \mathrm{a}$ & $13,30 \mathrm{~b}$ & $0,00 \mathrm{~b}$ \\
\hline MM & $8,80 \mathrm{~b}$ & 4,20 & c 5,80 bc & $28,50 \mathrm{a}$ & $0,00 \mathrm{~b}$ \\
\hline MR & $7,80 \mathrm{~b}$ & 0,00 & c 0,00 & 0,00 & $23,00 \mathrm{a}$ \\
\hline
\end{tabular}

CV 33,7\%

*Médias seguidas pela mesma letra na vertical não diferem entre si pelo teste de Tukey (5\% de probabilidade).

$\mathrm{BAN}=$ banana $; \mathrm{CAJ}=$ caju; $\mathrm{MG}=$ manga; $\mathrm{MM}=$ mamão; $\mathrm{MR}=$ maracujá.

TABELA 2 - Atividade enzimática de isolados de Colletotrichum spp. por difusão em substratos sólidos específicos

\begin{tabular}{|c|c|c|c|c|}
\hline \multirow{2}{*}{ Isolado } & \multicolumn{4}{|c|}{ Atividade enzimática } \\
\hline & Amilolítica & Celulolítica & Lipolítica & Proteolítica \\
\hline BAN & $9,14 * b * *$ & $0,00 \quad \mathrm{c}$ & $5,04 \mathrm{~b}$ & $10,24 \mathrm{a}$ \\
\hline CAJ & 11,07 & $4,04 \mathrm{ab}$ & 13,09 a & $5,07 \mathrm{~b}$ \\
\hline MG & 11,86 & $3,00 \mathrm{~b}$ & $13,25 \mathrm{a}$ & $4,67 \mathrm{~b}$ \\
\hline MM & 22,50 a & $4,46 \mathrm{a}$ & $12,80 \mathrm{a}$ & 1,64 \\
\hline MR & 8,85 & $4,89 \mathrm{a}$ & $11,41 \mathrm{a}$ & 1,20 \\
\hline CV $(\%)$ & 21,84 & 22,58 & 10,06 & 25,18 \\
\hline
\end{tabular}

*Halo de degradação em mm.

***Médias seguidas pela mesma letra na vertical não diferem entre si pelo teste de Tukey ( $5 \%$ de probabilidade).

$\mathrm{BAN}=$ banana CAJ = caju; $\mathrm{MG}=$ manga $; \mathrm{MM}=$ mamão $; \mathrm{MR}=$ maracujá. são comuns em fungos, permitindo a hidrólise de amido, mas, pouco se sabe sobre a sua importância na patogênese. Fungos podem utilizar o amido como fonte de energia para o crescimento e esporulação (Griffin, 1994). No entanto, a produção de amilase por fungos filamentosos varia de acordo com o gênero e a espécie envolvida (Nwufo \& Fajola, 1988).

Os isolados MR e MM, diferiram significativamente do isolado $\mathrm{MG}$ quanto a atividade celulolítica. $\mathrm{O}$ isolado CAJ diferiu apenas do BAN, sendo que este último não mostrou habilidade em produzir esta enzima após cinco dias de incubação. Possivelmente, um maior período fosse necessário para esse isolado expressar a produção de celulase. A maior ou menor capacidade de fungos em produzir enzimas em substratos específicos, permite diferenciar isolados de uma mesma espécie de forma simples (Paterson \& Bridge, 1994). De maneira similar, Lima (2000) detectou a produção de celulase em isolados de C. graminicola Politis.

Quanto à atividade da enzima lipase (Tabela 2), detectada pela presença de halo opaco em torno das colônias, destacaram-se MG, CAJ, MM, MR, os quais diferiram do isolado BAN que apresentou a menor média $(5,04 \mathrm{~mm})$. Este fato pode ser de grande valia na taxonomia química de fungos, tendo em vista que a maior capacidade na produção de lipase foi mais evidente nos isolados de C. gloeosporioides, os quais diferiram significativamente de C. musae. De acordo com Hankin \& Anagnostakis (1975), o halo opaco é proveniente da formação de cristais de cálcio do ácido láurico, liberado pela ação da enzima ou pela completa degradação dos sais lipídicos em meios contendo sorbitol monolaurato (Tween 20) como substrato lipídico. Segundo Kolattukudy (1985), existem evidências de que a cutinase, uma lipase capaz de degradar a cutina, esteja diretamente envolvida na penetração do fungo pela cutícula, desempenhando papel importante na patogenicidade.

A enzima protease tornou-se evidente durante a degradação do meio específico, sobre o qual todos os isolados testados mostraram capacidade em produzi-la, com destaque para o isolado BAN $(10,24 \mathrm{~mm})$ que causou o maior halo de degradação, diferindo dos demais isolados CAJ, MG, MM e MR. Estes dois últimos apresentaram os menores halos translúcidos de degradação, formados em torno das colônias. Conforme Hancock \& Millar (1965), a atividade patogênica de alguns fungos está diretamente relacionada com sua capacidade de produzir enzimas degradadoras da parede celular. A patogenicidade de $C$. musae em frutos de caju, manga e mamão, poderia estar correlacionado com a alta produção de protease demonstrada por este fungo, sendo possível diferenciá-lo dos demais isolados testados. Corroborando com este estudo, Couto (2002) verificou que isolados de C. musae obtidos de banana demonstraram maior atividade proteolítica que amilolítica, celulolítica e lipolítica.

Com relação aos padrões eletroforéticos analisados (Figura 1), os sistemas proteínas totais, $\alpha$-esterase, $\beta$-esterase e fosfatase ácida apresentaram polimorfismo, sendo mais pronunciado nos três primeiros, demonstrando a diversidade na base genética dos isolados, enquanto que as bandas de 


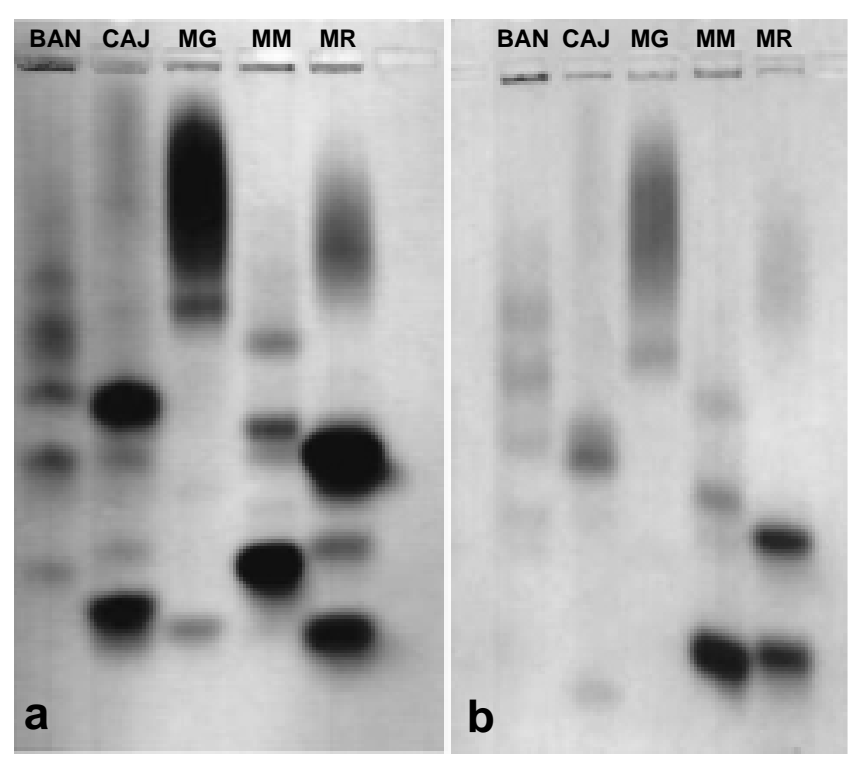

FIG. 1 - Padrões isoenzimáticos dos isolados (BAN, CAJ, MG, MM, MR) de Colletotrichum spp. em gel de poliacrilamida: a) $\alpha$-esterase; b) $\beta$-esterase. $\mathrm{BAN}=$ banana (Musa spp.); $\mathrm{CAJ}=$ caju (Anacardium occidentale) $; \mathrm{MG}=$ manga (Mangifera indica) $; \mathrm{MM}=$ mamão $($ Carica papaya); MR = maracujá (Passiflora edulis f. flavicarpa).

leucina aminopeptidase mostraram-se monomórficas, sem variação na intensidade de coloração e pouca variação na mobilidade relativa. Em relação a esta última enzima, trabalhos têm demonstrado o comportamento monomórfico dos padrões enzimáticos de fungos neste sistema (Gurgel et al., 2000; Silveira \& Alfenas, 2002).

Analisando o perfil de proteínas totais, os isolados mostraram variação quanto ao número, intensidade e mobilidade relativa (Rf) das bandas. Foram detectadas de sete a dez bandas, predominando dez nos isolados MG e $\mathrm{MM}$, tendo o isolado MR apresentado o menor número (sete bandas) de intensidade fraca, média, forte. Entre os isolados, foram verificadas bandas em comum nas diferentes regiões do gel, mostrando a relação intraespecífica (CAJ, MG, MM, MR). Porém, bandas de mobilidade distintas também foram observadas em todos os isolados, com destaque para o isolado MM, evidenciando quatro bandas nas posições $\mathrm{Rf} 6$, 15,18 e 25, ausentes nos demais isolados. Quanto ao isolado MR, este distingue-se dos demais pelo número de bandas (sete) e uma banda de intensidade forte $(\operatorname{Rf} 41,3)$.

$\mathrm{Na}$ análise do sistema $\alpha$-esterase (Figura 1a) foi observado variação na intensidade de coloração, número e mobilidade das bandas no gel. O número de bandas entre os isolados variou de três (MG, MR) a cinco (BAN, CAJ, MM). Quanto à mobilidade relativa, foi verificado expressiva variação na posição das bandas entre todos os isolados, com exceções da posição de migração 57,9 (BAN, CAJ e MR) e 73,7 (BAN e MM), com bandas em comum, diferindo pela intensa coloração da banda apresentada por MR e MM, o que sugere maior concentração da enzima e atividade da molécula. De acordo com Lima \& Menezes (2002), além da mobilidade relativa, existem outros fatores a serem considerados, como concentração da enzima refletida pela coloração forte e largura da banda formada. Os valores dos Rfs revelaram o comportamento polimórfico das moléculas de $\alpha$-esterase, apresentando diferenças intraespecíficas presentes entre os isolados de C. gloeosporioides. Estes resultados estão de acordo com os obtidos por Kaufmann \& Weidmann (1996), que verificaram marcante polimorfismo entre populações de $C$. gloeosporioides de diferentes hospedeiros e de diferentes localidades. Da mesma forma, Furtado et al. (1999) utilizando este sistema, distinguiram isolados de $C$. gloeosporioides, em relação ao órgão da planta de origem.

No sistema $\beta$-esterase (Figura $1 \mathrm{~b}$ ), todos os isolados mostraram expressiva variação quanto à mobilidade relativa e intensidade de coloração das bandas, exceto o isolado MG que apresentou uma única banda de intensidade fraca com mobilidade relativa distinta ( $\operatorname{Rf} 37,8)$. O número de bandas variou de uma a quatro, com predominância de três bandas. $\mathrm{O}$ isolado BAN apresentou o maior número de bandas distintas (Rf 32; 41,1; 48,9; 58,9), demonstrando variação interespecífica. Por este sistema, foi possível distinguir variação inter e intraespecífica nos isolados de Colletotrichum spp. usados. Resultados semelhantes foram obtidos por Lima (2000), identificando variabilidade intraespecífica nos isolados de C. graminicola constatado no sistema $\beta$-esterase.

Quanto ao sistema fosfatase ácida, o número de bandas variou de duas a três, com predominância de três bandas (CAJ, MG, MM). O isolado MM apresentou duas bandas distintas ( Rf 20; 28,9), mostrando os demais isolados bandas similares dispostas nas diferentes regiões do gel (Rf $13 ; 15,6 ; 22 ; 31,1)$. Resultados discordantes foram obtidos por Silva-Mann et al. (2002), que diferenciaram isolados de Colletotrichum gossypii (South) var. cephalosporioides A.S. Costa, através dos padrões de bandas desta enzima. Porém, Lima \& Menezes (2002) trabalhando com C. graminicola, observaram duas bandas da enzima com variação na intensidade e posição do gel em todos os isolados analisados.

Os dados dos coeficientes de similaridade para proteínas totais mostram que a maior relação ocorreu entre os isolados BAN e MG $(63,2 \%)$ (Tabela 3). No sistema $\alpha-$ esterase (Tabela 4), a maior similaridade foi observada entre MG e CAJ (100\%) a qual pode estar correlacionada com a patogenicidade (Tabela 1) e produção de enzimas hidrolíticas (Tabela 2), tendo em vista que os mesmos apresentaram resultados semelhantes. Para o sistema $\beta$-esterase, que mostrou alto nível de polimorfismo, os isolados MR e MM apresentaram similaridade de 33,3\%. As demais combinações não apresentaram bandas comuns e por isso, os coeficientes de similaridade foram nulos. Como as isoenzimas são formas moleculares múltiplas de uma mesma enzima, podem diferir na sequência de aminoácidos, influenciando no padrão de bandas em relação a outros isolados de uma mesma espécie (Ferreira \& Grattapaglia, 1996). O fato mostra a importância da utilização de vários sistemas para detecção das enzimas 


\section{R.M. Lima Filho et al.}

produzidas pelos fungos fitopatogênicos, permitindo a diferenciação a níveis subespecíficos, difíceis de serem observados por meio de marcadores morfológicos (Lima \& Menezes, 2002).

TABELA 3 - Coeficientes de similaridade de proteínas totais entre isolados de Colletotrichum spp.

\begin{tabular}{lccccc}
\hline \hline \multirow{2}{*}{ Isolado } & \multicolumn{5}{c}{ Coeficiente de Similaridade (\%)* } \\
\cline { 2 - 6 } & BAN & CAJ & MG & MM & MR \\
\hline BAN & - & 47,1 & 63,2 & 31,6 & 25,0 \\
CAJ & & - & 44,4 & 44,4 & 13,3 \\
MG & & & - & 40,0 & 35,3 \\
MM & & & & - & 47,1 \\
MR & & & & & -
\end{tabular}

${ }^{*} \mathrm{Cs}=2(\mathrm{bc} / \mathrm{b} 1+\mathrm{b} 2) \times 100$ (Hansen et al., 1986).

$\mathrm{BAN}=$ banana $; \mathrm{CAJ}=$ caju; $\mathrm{MG}=$ manga $; \mathrm{MM}=$ mamão $; \mathrm{MR}=$ maracujá .

TABELA 4 - Coeficientes de similaridade de $\alpha$-esterase entre isolados de Colletotrichum spp.

\begin{tabular}{lccccc}
\hline \hline \multirow{2}{*}{ Isolado } & \multicolumn{5}{c}{ Coeficiente de Similaridade (\%)* } \\
\cline { 2 - 6 } & BAN & CAJ & MG & MM & MR \\
\hline BAN & - & 80 & 80 & 0 & 0 \\
CAJ & & 100 & 0 & 40 \\
MG & & - & 0 & 40 \\
MM & & & - & 40 \\
MR & & & \\
*Cs = 2(bc/b1 + b2) x 100 (Hansen et al., 1986). \\
BAN = banana; CAJ = caju; MG = manga; MM = mamão; MR = maracujá.
\end{tabular}

\section{REFERÊNCIAS BIBLIOGRÁFICAS}

ALFENAS, A.C., PETERS, I., BRUNE, W. \& PASSADOR, G.C. Eletroforese de proteínas e isoenzimas de fungos e essências florestais. Viçosa. Universidade Federal de Viçosa. 1991.

BAILEY, J. A., O'CONNELL, R.J., PRING, R.J., \& NASH, C. Infection strategies of Colletotrichum species. In: Bailey, J.A. \& Jeger, M.J. (Eds.) Colletotrichum: biology, pathology and control. Wallingford. CAB International. 1992. pp.88-120.

BENATO, E.A. Controle de doenças pós-colheita em frutas tropicais. Summa Phytopathologica 25:90-92.1999.

BOSHOFF, W.H.P., SWUART,W.J., PRETORIUS, Z.A., LIEBENBERG, M.M. \& CRONS, P.W. Isozyme variability among isolates of Phaeoisariopsis griseola in southern Africa. Plant Disease 45:344-349. 1996.

COUTO, E.F. Estudo comparativo de isolados de Colletotrichum musae através de caracteres patogênicos, enzimáticos, fisiomorfológicos e molecular. (Tese de Mestrado). Recife. Universidade Federal Rural de Pernambuco. 2002.

DENOYES, B. \& BAUDRY, A. Species identification and pathogenicity study of French Colletotrichum strains isolated from strawberry using morphological and cultural characteristics. Phytopathology 85:53-57. 1995.

DIANESE, J.C. Patologia vegetal: agressão e defesa em sistemas planta-patógeno. Brasília. Editora Universidade de Brasília. 1990.

FERREIRA, M.E. \& GRATTAPAGLIA, D. Introdução ao uso de marcadores moleculares em análise genética. Brasília. EMBRAPASPI. 1996.

FURTADO, E.L., BACH, E.B., KIMATI, H., MENTEN, J.O.M. \& SILVEIRA, A.P. Caracterização morfológica, patogênica e isoenzimática de isolados de Colletotrichum gloeosporioides de seringueira. Summa Phytopathologica 25:222-227. 1999.

GRIFFIN, D.H. Fungal physiology. $2^{\mathrm{a}}$ ed. New York. John Wiley \& Sons, Inc. 1994.

GURGEL, L.M.S., MENEZES, M. \& COÊLHO, R.S.B. Diferenciação de Phomopsis anacardii e Phomopsis mangiferae por padrões eletroforéticos de proteínas e isoenzimas. Summa Phytopathologica 26:435-439. 2000.

HANCOCK, J.G. \& MILLAR, R.L. Association of cellulolytic, proteolytic, and xylolitic enzymes with southern anthracnose, springs black stem, and Stemphylium leaf spot of alfalfa. Phytopathology 55:356-360. 1965.

HANKIN, L. \& ANAGNOSTAKIS, S.L. The use of solid media for detection of enzyme production by fungi. Mycologia 67:597-607. 1975.

HANSEN, E.M., BRASIER, C.M., SHAW, D.S. \& HAMM, P.B. The taxonomic structure of Phytophthora megasperma: evidence for emerging biological species groups. Transactions of the British Mycological Society 87:557-573. 1986.

KAUFMANN, P.J. \& WEIDMANN, G.J. Isozyme analysis of Colletotrichum gloeosporioides from five host genera. Plant Disease 80:1289-1293. 1996.

KOLATTUKUDY, P.E. Enzymatic penetration of the plant cuticule by fungal pathogens. Annual Review of Physiophatology 23:223250. 1985.

LIMA, M.L.F. Caracterização patogênica, fisiológica e enzimática de isolados de C. graminicola (Ces.) G.W. Wilson agente causal da antracnose do milho, Zea mays L., 2000. (Tese de Mestrado). Recife. Universidade Federal de Pernambuco. 2000.

LIMA, M.L.F. \& MENEZES, M. Estudo comparativo de isolados de Colletotrichum graminicola através da análise eletroforética de padrões protéicos e isoenzimáticos. Fitopatologia Brasileira 27:1216. 2002.

LIMA, M.I.P.M., GASPOROTO, L. \& SANTOS, A. Controle químico da antracnose do maracujazeiro. Manaus. EMBRAPAMARA. Comunicado técnico 05, 1993.

MICALES, J.A., BONDE, R. \& PETERSON, G.L. Isozyme analysis and aminopeptidase activities within the genus Peronosclerospora. Phytopathology 78:1396-1402. 1988.

MUNIZ, M. de F.S., SANTOS, R.de C.R. dos \& BARBOSA, G.V. de S. Patogenicidade de isolados de Colletotrichum gloeosporioides sobre algumas plantas frutíferas. Summa Phytopathologica 24:177179. 1998.

NEIROTTI, E. \& AZEVEDO, J.L. Técnica semiquantitativa de avaliação de produção de celulase em Humicola sp. Revista de Microbiologia 19:78-81. 1988.

NWUFO, M.I. \& FAJOLA, A.O. Production of amylolytic enzymes in culture by Botryodiplodia theobromae and Sclerotium rolfsii 
Caracterização enzimática e patogenicidade cruzada de Colletotrichum spp. associados...

associated with the corn rots of Colocasia esculenta. Acta Microbiologica Hungarica 35:371-378. 1988.

PATERSON, R.R.M. \& BRIDGE, R.L.D.L. Biochemical techniques for filamentous fungi. Cambridge. CAB International. 1994.

PERES, N.A.R., KURAMAE, E.E., DIAS, M.S.C. \& SOUZA, N.L. de. Identification and characterization of Colletotrichum spp. affecting fruit after harvest in Brazil. Journal of Phytopathology 150:128-134. 2002.

SILVA-MANN, R., SALGADO, K.C.C., VIEIRA, M.G.G.C. \& MACHADO, J.C. Variabilidade genética de isolados do complexo
Colletotrichum associados a sementes de algodoeiro, por meio de técnicas moleculares e inoculações em plantas. Fitopatologia Brasileira 27:27-32. 2002.

SILVEIRA, S.F. \& ALFENAS, A.C. Análise de proteínas e isoenzimas de isolados de Rhizoctonia spp. patogênicas a Eucalyptus. Fitopatologia Brasileira 27:33-41. 2002.

SMITH, B.J. \& BLACK, L.L. Morphological, cultural, and pathogenic variation among Colletotrichum species isolated from strawberry. Plant Disease 74:69-76. 1990. 